\title{
Effect of Cr Substitution on Magnetic Properties of Mg Nanoferrites Synthesized by Citrate-Gel Auto Combustion Method
}

\author{
M. Raghasudha, ${ }^{1}$ D. Ravinder, ${ }^{2}$ and P. Veerasomaiah ${ }^{3}$ \\ ${ }^{1}$ Department of Chemistry, Jayaprakash Narayan College of Engineering, Mahabubnagar 509001, Andhra Pradesh, India \\ ${ }^{2}$ Department of Physics, Nizam College, Basheerbagh Osmania University, Hyderabad 500001, Andhra Pradesh, India \\ ${ }^{3}$ Department of Chemistry, Osmania University, Hyderabad 500007, Andhra Pradesh, India
}

Correspondence should be addressed to D. Ravinder; ravindergupta28@rediffmail.com

Received 14 May 2013; Revised 14 September 2013; Accepted 16 September 2013

Academic Editor: Theocharis C. Stamatatos

Copyright (c) 2013 M. Raghasudha et al. This is an open access article distributed under the Creative Commons Attribution License, which permits unrestricted use, distribution, and reproduction in any medium, provided the original work is properly cited.

A series of Mg-Cr nanoferrites with the chemical formula $\mathrm{MgCr}_{x} \mathrm{Fe}_{2-x} \mathrm{O}_{4}(0.0 \leq x \leq 1.0)$ were synthesized by Citrate-Gel auto combustion method. The formation of single phase cubic spinel structure of the samples was confirmed by X-ray diffraction (XRD) analysis. It is observed that with the increase in the paramagnetic Cr content, the particle size of the ferrite compositions has decreased from $23 \mathrm{~nm}$ to $7 \mathrm{~nm}$. Faraday magnetic Susceptibility Balance was used to measure the Magnetic susceptibility of synthesized samples that confirmed the paramagnetic nature of the ferrites. Vibrating Sample Magnetometer (VSM) was used to measure the Magnetic properties of nanoferrites under investigation at room temperature under the applied magnetic field of $15 \mathrm{kOe}$. With the increase in $\mathrm{Cr}^{3+}$ concentration, the saturation magnetization has decreased from $11 \mathrm{emu} / \mathrm{g}$ to $1.5 \mathrm{emu} / \mathrm{g}$.

\section{Introduction}

Spinel ferrites have gained much importance in recent years. As magnetic materials, ferrites cannot be replaced by any other magnetic material because they are relatively inexpensive, stable and have a wide range of technological applications in magnetic recording, transformer cores, sensors and magnetic resonance imaging, and so forth [1-3]. Nowadays, these materials are largely synthesized in nanometric scale for new and improved properties [4,5]. It is known that magnetic and electrical properties of ferrite materials are sensitive to their microstructure especially grain size and porosity [6]. Grain size depends on the method of preparation, reaction conditions, composition of ferrites, sintering temperature, and so forth. A number of physical and chemical techniques have been developed in recent years to prepare nanosized magnetic materials. The widely used chemical methods are electro deposition [7], coprecipitation [8], microemulsion technique [9], wet chemical method [10] double sintering technique [11], Citrate-gel method [12], and so forth. Among the various routes, Citrate-gel method yields more promising results in the synthesis of ultrafine particles at a fairly low temperature [13-15]. It is reported that the Citrate-gel method is a simple process which speeds up the synthesis of complex materials. It offers a significant saving in time and energy consumption over the traditional methods as it results in the nanoscale particles at a lower sintering temperature for a shorter time period.

For the past few decades, Magnesium ferrite has attracted the attention of researchers $[16,17]$ due to its great potential for a wide range of applications. These include microwave devices that are based on unique properties of these materials such as higher values of saturation magnetization, curie temperature, electrical resistivity, low Dielectric losses, and moderate coercive field. The excellent magnetic behavior of this material can be explained by the ordering of the magnetic moments of ferric ions and the strong exchange interactions [18].

In view of immense importance of magnesium ferrites and the fact that their properties undergo significant changes on substitution with metal cations, it is thought to synthesize Chromium doped Magnesium ferrites. Hankare et al. have 
synthesized Cr substituted Mg ferrites using coprecipitation method and their electrical and magnetic properties were studied [17]. Hashim et al. have synthesized nanoparticles of $\mathrm{Ni}_{0.5} \mathrm{Mg}_{0.5} \mathrm{Fe}_{2-x} \mathrm{Cr}_{x} \mathrm{O}_{4}(0 \leq x \leq 1.0)$ by Citrate-gel auto combustion method and studied their dielectric and magnetic properties [19]. It is under stood and is a fact that Citrategel auto combustion method results in ferrites with narrow particle size. To the authors' knowledge, little information is available on the $\mathrm{Mg}-\mathrm{Cr}$ nanoferrites synthesized using Citrate-Gel method. It is also known that by calcination the grain size of the $\mathrm{Mg}$-Cr ferrites exhibit different development trend which influences their properties much.

Therefore, an attempt has been made to synthesize $\mathrm{MgCr}_{x} \mathrm{Fe}_{2-x} \mathrm{O}_{4}$ spinel ferrite system by Citrate-gel auto combustion method to obtain nanocrystalline particles and to study the magnetic properties and the effect of calcination on the grain size of the particles. Magnetic properties of the nanosized ferrites play a vital role in making use of them in different fields. Hard magnetic materials are used in electric motors, magnetic recording media (e.g., hard drives, floppy disks, or magnetic tape), and magnetic separation. Magnetically soft materials are used in transformer and inductor cores, recording heads, microwave devices, and magnetic shielding. Available literature on the substituted Mg nanoferrites is scarce. A little information is available on the magnetic study of Chromium substituted $\mathrm{Mg}$ nanoferrites with low particle size. Therefore, in the present investigation, a maiden attempt has been made to investigate the effect of $\mathrm{Cr}^{3+}$ ions on the magnetic properties of $\mathrm{Mg}$ nanoferrites synthesized by Citrate-gel auto combustion method.

\section{Experimental Procedure}

2.1. Synthesis. The nanocrystalline ferrites of the chemical composition $\mathrm{MgCr}_{x} \mathrm{Fe}_{2-x} \mathrm{O}_{4}(x=0.0,0.1,0.3,0.5,0.7,0.9$ and 1.0) were prepared using Citrate-Gel auto combustion method [20]. The following chemicals are used as starting materials for the synthesis.

$$
\begin{aligned}
& \text { Magnesium Nitrate }\left(\mathrm{Mg}\left(\mathrm{NO}_{3}\right)_{2} 6 \mathrm{H}_{2} \mathrm{O}\right) \\
& \text { Ferric Nitrate }\left(\mathrm{Fe}\left(\mathrm{NO}_{3}\right)_{2} 9 \mathrm{H}_{2} \mathrm{O}\right) \text {, } \\
& \text { Chromium Nitrate }\left(\mathrm{Cr}\left(\mathrm{NO}_{3}\right)_{2} 9 \mathrm{H}_{2} \mathrm{O}\right) \text {, } \\
& \text { Citric acid }\left(\mathrm{C}_{6} \mathrm{H}_{8} \mathrm{O}_{7} \cdot \mathrm{H}_{2} \mathrm{O}\right) \text { and } \\
& \text { Ammonia }\left(\mathrm{NH}_{3}\right) \text { (all 99\% pure). }
\end{aligned}
$$

The as synthesized powders were subjected to sintering for four hours in muffle furnace at $500^{\circ} \mathrm{C}$.

2.2. Characterization. The structural characterization of as synthesized and sintered powders were carried out at room temperature by $\mathrm{X}$-ray diffractometer using $\mathrm{CuK} \alpha$ radiation $(\lambda=1.5405 \AA)$. The magnetic susceptibility of different compositions of $\mathrm{Mg}$ - $\mathrm{Cr}$ ferrites at room temperature were measured using Faraday's magnetic Balance which showed the paramagnetic nature of $\mathrm{Mg}$-Cr ferrites. The magnetic properties of synthesized Chromium substituted Mg nanoferrites were studied using Vibrating Sample Magnetometer
TABLE 1: Crystallite size of as synthesized and heat treated $\mathrm{MgCr}_{x} \mathrm{Fe}_{2-x} \mathrm{O}_{4}$ nanoferrites $(x=0.0,0.1,0.3,0.5,0.7,0.9$, and 1.0 ).

\begin{tabular}{lcc}
\hline Composition & $\begin{array}{c}\text { Crystallite size of as } \\
\text { synthesized samples }(\mathrm{nm})\end{array}$ & $\begin{array}{c}\text { Crystallite size of heat } \\
\text { treated samples }(\mathrm{nm})\end{array}$ \\
\hline $\mathrm{MgFe}_{2} \mathrm{O}_{4}$ & 29.62 & 23.46 \\
$\mathrm{MgCr}_{0.1} \mathrm{Fe}_{1.9} \mathrm{O}_{4}$ & 26.00 & 08.89 \\
$\mathrm{MgCr}_{0.3} \mathrm{Fe}_{1.7} \mathrm{O}_{4}$ & 28.00 & 09.00 \\
$\mathrm{MgCr}_{0.5} \mathrm{Fe}_{1.5} \mathrm{O}_{4}$ & 18.69 & 07.17 \\
$\mathrm{MgCr}_{0.7} \mathrm{Fe}_{1.3} \mathrm{O}_{4}$ & 17.36 & 08.13 \\
$\mathrm{MgCr}_{0.9} \mathrm{Fe}_{1.1} \mathrm{O}_{4}$ & 16.20 & 07.64 \\
$\mathrm{MgCrFeO}_{4}$ & 15.30 & 07.60 \\
\hline
\end{tabular}

(VSM) at room temperature under the applied magnetic field of $15 \mathrm{kOe}$.

\section{Results and Discussions}

3.1. X-Ray Diffraction Studies. X-ray diffraction patterns of all the samples confirm the formation of a well-defined single-phase cubic spinel structure without any impurity peak [21]. From the XRD patterns it is clear that the as prepared powder is also in single phase with a spinel structure indicating that the ferrite can be directly formed after the auto combustion of the gel without heat treatment. The broad peaks in the XRD patterns indicate a fine particle nature of the particles.

The average particle size of the different compositions of the as synthesized $\mathrm{Mg}-\mathrm{Cr}$ ferrites and calcined $\mathrm{Mg}-\mathrm{Cr}$ ferrites were calculated from Scherrer formula [22], using the maximum intensity peak (311), and were shown in Table 1.

From the table it is clear that nanosized $\mathrm{Mg}$-Cr ferrite powders can be directly synthesized by Citrate-gel auto combustion method. From the XRD patterns [21] it is clear that the positions of the reflection peaks for as-burnt powders and heat treated powders are almost identical that implies that the basic structure of the nanoparticles is the same as that of the bulk material. Comparing XRD patterns of as synthesized and heat treated samples, it was found that the samples with the same composition differ only in the relative intensity. Similar behavior was reported in synthesis of $\mathrm{MgCuZn}$ ferrites using sol-gel auto combustion method by Qi et al. [22].

3.2. Magnetic Susceptibility Using Faradays Balance. The degree of magnetization of a material in response to an applied magnetic field can be indicated by a dimension less proportionality constant known as magnetic susceptibility. A substance will produce its own magnetic field when placed in an external magnetic field. The field adds to the applied field, if the substance is paramagnetic. If the substance is diamagnetic, this field subtracts from the main field. This contribution to the external magnetic field is known as the magnetic susceptibility of the substance. A very sensitive instrument known as a Faradays magnetic susceptibility balance is used to measure magnetic susceptibility of heat 
treated $\mathrm{Mg}$-Cr nanoferrites at room temperature. In the Faraday balance, the field is inhomogeneous. The pole pieces of the magnet are so shaped that there is a region in which the product of the field strength and field gradient in the $z$ direction is constant. The sample is placed in this region. The force in this case is independent of the packing of the sample and depends only on the total mass of the material present. The method is sensitive and highly reproducible and can be applied to single crystals. Using a magnetic balance, the force is measured as a weight change. To calibrate the field gradient the force experienced by a standard sample is measured for different dial settings on the magnet power supply. The sample used for this purpose was Mercury tetra thiocyanato Cobaltate $\mathrm{Hg}\left[\mathrm{Co}(\mathrm{SCN})_{4}\right]$ which is known to have a gram susceptibility of $16.44 \times 10^{-6} \mathrm{cgs}$ units at $20^{\circ} \mathrm{C}$ [23]. Paramagnetic materials are attracted to an external magnetic field and give a positive reading. Diamagnetic materials are weakly repelled by an external magnetic field, resulting in a negative reading. The gram magnetic susceptibility $\left(\chi_{g}\right)$ for a substance may be calculated from the following equation.

$$
\chi_{g}=\left(\chi_{g}\right)_{s}\left(\frac{w_{s}}{\Delta w_{s}}\right)\left(\frac{\Delta w_{c}}{w_{c}}\right),
$$

where $\chi_{g}=$ gram susceptibility of compound; $\left(\chi_{g}\right)_{s}=$ gram susceptibility of standard sample $=16.44 \times 10^{-6} \mathrm{cgs}$ units at $20^{\circ} \mathrm{C} ; W_{s}=$ weight of the standard sample in absence of magnetic field; $W_{c}=$ weight of the compound in absence of magnetic field; $\Delta w_{s}=$ change in weight of the standard sample after the applied magnetic field; $\Delta w_{c}=$ change in weight of the compound after the applied magnetic field.

From the gram magnetic susceptibility, the Molar magnetic susceptibility $\left(\chi_{m}\right)$ is calculated using the following equation:

$$
\chi_{m}=\chi_{g} \text { (Molecular weight) } .
$$

The magnetic susceptibility for a particular substance is not particularly useful as itself. $\chi_{m}$ value comprises between $10^{-5}$ and $10^{-6}$ for paramagnetic substances and it comprises between $-10^{-5}$ and $-10^{-6}$ for diamagnetic substances.

The effective magnetic moment for a particular substance can be calculated from the gram magnetic susceptibility using the following equation.

$$
\mu_{\mathrm{eff}}=2.83\left(\chi_{m} \cdot T\right)^{1 / 2} \mathrm{BM}
$$

where $\mu_{\text {eff }}=$ effective magnetic moment in Bohr Magnetons (BM), $\chi_{m}=$ Molar magnetic susceptibility, and $T=$ absolute temperature.

The Molar susceptibility and Effective magnetic moment for various compositions of heat treated $\mathrm{Mg}$-Cr nanoferrites at room temperature were calculated using the above equations and were tabulated in Table 2.

From the Table 2 it is clear that the molar susceptibility values of $\mathrm{Mg}$-Cr ferrites of various compositions are of the order of $10^{-6}$ indicating the paramagnetic nature of $\mathrm{Mg}$ $\mathrm{Cr}$ ferrite system. Further, the effective magnetic moment calculated for various samples shows that $\mu_{\text {eff }}$ decreases

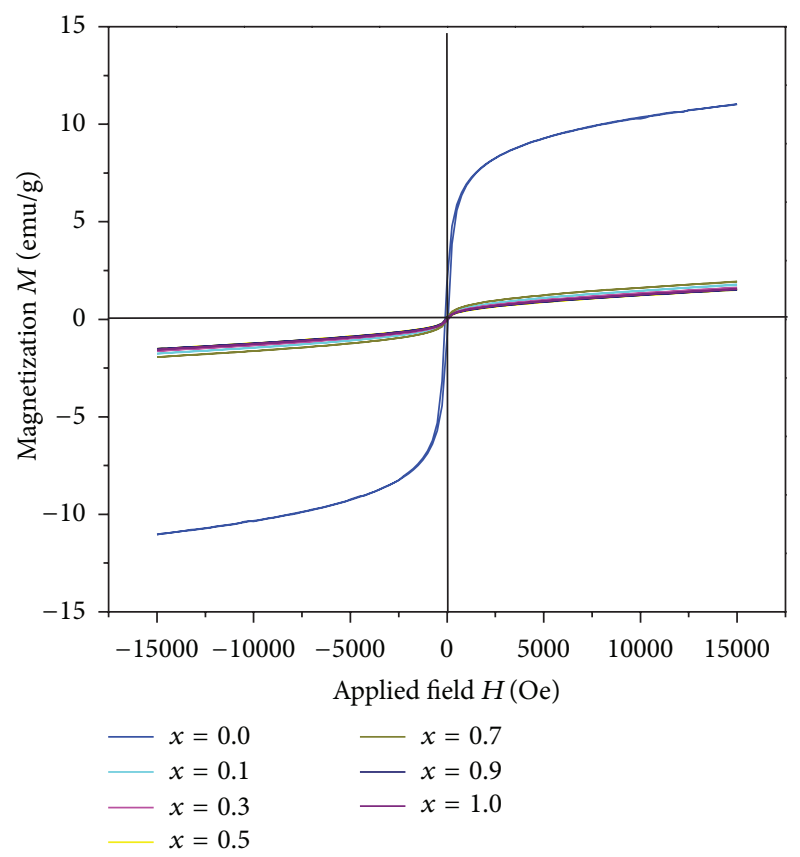

Figure 1: $M-H$ curves for $\mathrm{MgCr}_{x} \mathrm{Fe}_{2-x} \mathrm{O}_{4}(x=0.0,0.1,0.3,0.5,0.7$, 0.9 , and 1.0) nanoparticles synthesized by Citrate-gel technique.

TABLE 2: Molar susceptibility $\left(\chi_{m}\right)$ and effective magnetic moment $\left(\mu_{\text {eff }}\right)$ of $\mathrm{MgCr}_{x} \mathrm{Fe}_{2-x} \mathrm{O}_{4}(x=0.0,0.1,0.3,0.5,0.7,0.9$, and 1.0).

\begin{tabular}{lcc}
\hline Composition & $\chi_{m}$ (cgs units) & $\mu_{\text {eff }}(\mathrm{BM})$ \\
\hline $\mathrm{MgFe}_{2} \mathrm{O}_{4}$ & $533554.66 \times 10^{-6}$ & 36.099 \\
$\mathrm{MgCr}_{0.1} \mathrm{Fe}_{1.9} \mathrm{O}_{4}$ & $59274.36 \times 10^{-6}$ & 12.033 \\
$\mathrm{MgCr}_{0.3} \mathrm{Fe}_{1.7} \mathrm{O}_{4}$ & $53577.95 \times 10^{-6}$ & 11.439 \\
$\mathrm{MgCr}_{0.5} \mathrm{Fe}_{1.5} \mathrm{O}_{4}$ & $41808.91 \times 10^{-6}$ & 10.106 \\
$\mathrm{MgCr}_{0.7} \mathrm{Fe}_{1.3} \mathrm{O}_{4}$ & $57593.24 \times 10^{-6}$ & 11.861 \\
$\mathrm{MgCr}_{0.9} \mathrm{Fe}_{1.1} \mathrm{O}_{4}$ & $42148.22 \times 10^{-6}$ & 10.145 \\
$\mathrm{MgCrFeO}_{4}$ & $42316.89 \times 10^{-6}$ & 10.165 \\
\hline
\end{tabular}

with increase in the concentration of dopant $\mathrm{Cr}^{3+}$. The magnetic behavior was further studied from the hysteresis loops obtained from VSM measurements.

3.3. Magnetic Properties Using VSM. The magnetic measurements of various compositions of heat treated $\mathrm{Mg}$ Cr nanoferrites were measured by using Vibrating Sample Magnetometer at room temperature in the range of $15 \mathrm{kOe}$. Figure 1 show the magnetic hysteresis loops for the heat treated $\mathrm{Mg}$-Cr ferrite samples obtained from Vibrating Sample Magnetometer measurements at room temperature. The relation between the Magnetization $(M)$ and the applied field $(H)$ is given by Hysteresis loops. Various magnetic parameters extracted from the hysteresis loops are Saturation Magnetization- $M_{s}$ (maximum value of magnetization), Remanence Magnetization- $M_{r}$ (magnetization at zero field), Coercivity $H_{c}$ (magnetic field required to reduce the magnetization of that material to zero after the magnetization of the sample has been driven to saturation), Remanence ratio or Squareness ratio $\left(M_{r} / M_{s}\right)$. The magnetic parameters of all 


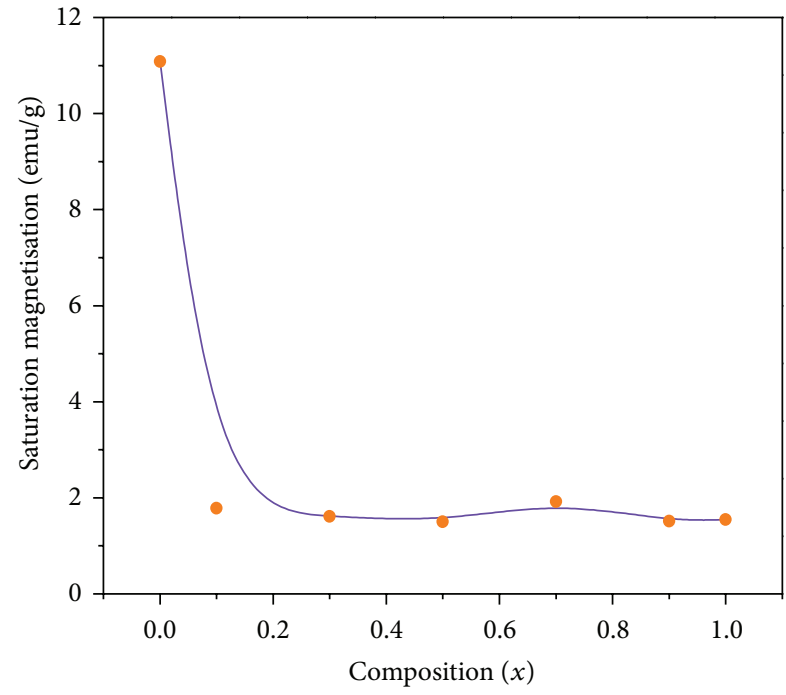

(a)

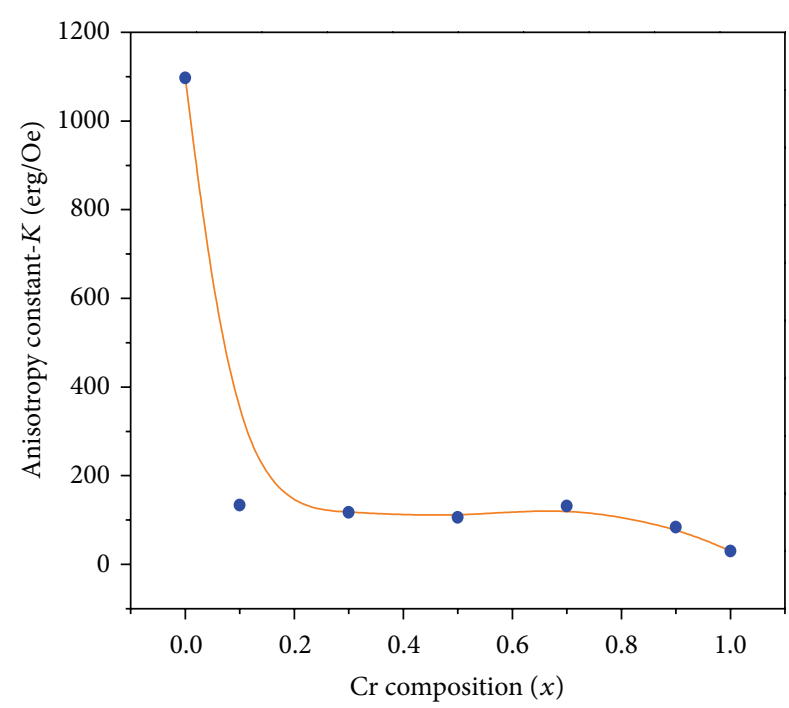

(b)

FIGURE 2: (a) variation of Saturation Magnetization with composition. (b) variation of anisotropy constant with composition.

TABLE 3: Magnetic parameters from Hysteresis loops.

\begin{tabular}{|c|c|c|c|c|}
\hline Composition & $\begin{array}{l}\text { Saturation magnetization } \\
\qquad M_{s}(\mathrm{emu} / \mathrm{g})\end{array}$ & $\begin{array}{c}\text { Remanent Magnetization } \\
M_{r}(\mathrm{emu} / \mathrm{g})\end{array}$ & $\begin{array}{c}\text { Coercivity } H_{c} \\
(\mathrm{Oe})\end{array}$ & Remanence ratio $=M_{r} / M_{s}$ \\
\hline $\mathrm{MgFe}_{2} \mathrm{O}_{4}$ & 11.08 & 1.794 & 97.06 & 0.16 \\
\hline $\mathrm{MgCr}_{0.1} \mathrm{Fe}_{1.9} \mathrm{O}_{4}$ & 1.783 & 0.112 & 73.522 & 0.06 \\
\hline $\mathrm{MgCr}_{0.3} \mathrm{Fe}_{1.7} \mathrm{O}_{4}$ & 1.61 & 0.029 & 71.32 & 0.02 \\
\hline $\mathrm{MgCr}_{0.5} \mathrm{Fe}_{1.5} \mathrm{O}_{4}$ & 1.502 & 0.058 & 69.08 & 0.04 \\
\hline $\mathrm{MgCr}_{0.7} \mathrm{Fe}_{1.3} \mathrm{O}_{4}$ & 1.918 & 0.117 & 67.08 & 0.06 \\
\hline $\mathrm{MgCr}_{0.9} \mathrm{Fe}_{1.1} \mathrm{O}_{4}$ & 1.517 & 0.082 & 54.07 & 0.05 \\
\hline $\mathrm{MgCrFeO}_{4}$ & 1.546 & 0.025 & 19.02 & 0.02 \\
\hline
\end{tabular}

the samples of $\mathrm{Mg}-\mathrm{Cr}$ ferrites were calculated from $M$ $H$ loops and were tabulated in Table 3 and are used to characterize the magnetic properties of materials.

Both the saturation magnetization and coercivity decrease with increase in $\mathrm{Cr}^{3+}$ content as evident from Figure 2 and Table 3 . The magnetic properties of soft ferrites are influenced by the composition and microstructure of the materials. Among these factors the microstructure has great effect on the magnetic properties.

It is believed that the larger the grain size, the higher the saturation magnetization [22]. From Table 1, $\mathrm{MgFe}_{2} \mathrm{O}_{4}$ ferrites have larger grain size $(23 \mathrm{~nm})$, hence greater saturation magnetization. With increase in $\mathrm{Cr}$ concentration the grain size has decreased hence the saturation magnetization values have also decreased. The saturation magnetization $\left(M_{s}\right)$ at room temperature decreased from $11.08 \mathrm{emu} / \mathrm{g}$ to $1.546 \mathrm{emu} / \mathrm{g}$ due to the doping of $\mathrm{Cr}^{3+}$ ions in $\mathrm{Mg}$-Cr ferrites. This decrease in $M_{s}$ value may also be explained due to the fact that the $\mathrm{Fe}^{3+}$ (magnetic moment $5 \mu \mathrm{B}$ ) are replaced by lesser magnetic $\mathrm{Cr}^{3+}$ ions (magnetic moment $3 \mu \mathrm{B}$ ) in the octahedral (B) sites of the ferrite sub lattice. An increase in the concentration of $\mathrm{Cr}^{3+}$ ion decreases the $\mathrm{Fe}^{+3}(\mathrm{~B}) / \mathrm{Fe}^{+2}(\mathrm{~A})$ ratio that is, $\mathrm{A}-\mathrm{B}$ super exchange interaction decreases [24]. Variation of Saturation Magnetization with composition of $\mathrm{Mg}-\mathrm{Cr}$ ferrites is shown in Figure 2(a).

The value of coercivity $\left(H_{c}\right)$ decreased from $97.06 \mathrm{Oe}$ to 19.02 Oe with increase in $\mathrm{Cr}^{3+}$ concentration which may be due to the decrease in anisotropy field which in turn decreases the domain wall energy [25]. From the values of coercivity $\left(H_{c}\right)$ and the saturation magnetization $\left(M_{s}\right)$ anisotropy constant $K$ can be calculated using the following relation [26], and were tabulated in Table 4.

$$
H_{c}=\frac{0.98 K}{M_{s}}
$$

The magnetic moment per formula unit in Bohr Magneton $\left(\mu_{B}\right)$ was calculated using the following relation [27] and were tabulated in Table 4.

$$
\mu_{B}=\frac{M x M_{s}}{5585}
$$

where $M$ is the molecular weight of the sample and $M_{s}$ is the saturation magnetization.

From Table 4 it is clear that with increase in $\mathrm{Cr}^{3+}$ concentration the magnetic moment values decrease. This shows 
TABLE 4: Anisotropy constant and magnetic moment values for various $\mathrm{Mg}$-Cr ferrites.

\begin{tabular}{lcc}
\hline Composition & $\begin{array}{c}\text { Anisotropy constant } K \\
\text { (erg/Oe) }\end{array}$ & $\begin{array}{c}\text { Magnetic moment } \\
(\mathrm{BM})\end{array}$ \\
\hline $\mathrm{MgFe}_{2} \mathrm{O}_{4}$ & 1097.372 & 0.3968 \\
$\mathrm{MgCr}_{0.1} \mathrm{Fe}_{1.9} \mathrm{O}_{4}$ & 133.765 & 0.0637 \\
$\mathrm{MgCr}_{0.3} \mathrm{Fe}_{1.7} \mathrm{O}_{4}$ & 117.169 & 0.0573 \\
$\mathrm{MgCr}_{0.5} \mathrm{Fe}_{1.5} \mathrm{O}_{4}$ & 105.876 & 0.0533 \\
$\mathrm{MgCr}_{0.7} \mathrm{Fe}_{1.3} \mathrm{O}_{4}$ & 131.285 & 0.0677 \\
$\mathrm{MgCr}_{0.9} \mathrm{Fe}_{1.1} \mathrm{O}_{4}$ & 83.698 & 0.0534 \\
$\mathrm{MgCrFeO}_{4}$ & 30.005 & 0.0543 \\
\hline
\end{tabular}

the paramagnetic behavior of the ferrites under investigation. Figure 2(b) shows the variation of anisotropy constant $K$ with $\mathrm{Cr}^{3+}$ concentration. It is seen that the value of anisotropy constant, $K$ decreases with increase in $\mathrm{Cr}^{3+}$ concentration.

Hysteresis curves are used to check the difference between the soft magnetic materials and the hard magnetic materials. The area inside the hysteresis loop is large for a hard magnetic material, as it represents the amount of useful magnetic energy that can be made available to do work. But, for a soft magnetic material the area inside the loop is small that a small amount of energy is dissipated in repeatedly reversing the magnetization. In the present work, from the hysteresis loops, it is confirmed that soft magnetic materials were prepared with low coercivity.

\section{Conclusions}

(i) Using Citrate-gel auto combustion technique a series of $\mathrm{MgCr}_{x} \mathrm{Fe}_{2-x} \mathrm{O}_{4}(0.0 \leq x \leq 1.0)$ nanoparticles have been synthesized.

(ii) Nanocrystalline ferrite powders with low cost were prepared in this process that takes very less time and low sintering temperature.

(iii) The XRD pattern revealed that the cubic spinel structure is maintained for all compositions of both as synthesized powders and heat treated ferrite powders.

(iv) The particle size was in the range of 7 to $23 \mathrm{~nm}$ that has decreased with increase in $\mathrm{Cr}^{3+}$ compositions.

(v) Magnetic susceptibility measurement by Faradays magnetic Balance indicates the paramagnetic nature of the nanosized $\mathrm{Mg}$-Cr ferrites.

(vi) Incorporation of $\mathrm{Cr}^{3+}$ ions in $\mathrm{Mg}$ Ferrites results in decrease in particle size, Saturation Magnetization, coercivity, and magnetic moment because the replacement of $\mathrm{Fe}^{3+}$ by $\mathrm{Cr}^{3+}$ ions weakens the sublattice interaction and lowers magnetic moments of unit cells.

(vii) $\mathrm{Mg}$-Cr nanoferrites with narrow hysteresis loop were synthesized with low saturation magnetization and low coercivity. Hence, these ferrites are magnetically soft materials. (viii) These characteristics of ferrites are desirable for their utility in transformers, inductor cores, recording heads, microwave devices, and magnetic shielding.

\section{Acknowledgments}

The authors are grateful to K. S. Ravikumar, Chairman, at Jayaprakash Narayan College of Engineering, Mahabunagar (Dist) for his support and continuous encouragement in carrying out research work. D.Ravinder is grateful to Prof. T. L. N. Swamy, Principal Nizam College, for his encouragement to carry out this research work. The authors are also thankful to Prof. M. Vithal, Department of Chemistry, O.U., for his support in characterization of samples.

\section{References}

[1] J. Kulikowski, "Soft magnetic ferrites-development or stagnation?" Journal of Magnetism and Magnetic Materials, vol. 41, no. $1-3$, pp. 56-62, 1984.

[2] M. Sugimoto, “The past, present, and future of ferrites," Journal of the American Ceramic Society, vol. 82, no. 2, pp. 269-280, 1999.

[3] I. Safarik, M. Safarikova, H. Hofmann, Z. Rahman, and U. Schubert, Eds., Nanostructured Materials, 2002.

[4] V. Sepelak, D. Baabe, and D. Mienert, "Evolution of structure and magnetic properties with annealing temperature in nanoscale high-energy-milled nickel ferrite," Journal of Magnetism and Magnetic Materials, vol. 257, no. 2-3, pp. 377-386, 2003.

[5] M. Pavlovic, C. Jovalihic, A. S. Nikolic, D. Manojlovic, and N. Sojic, "Mechanochemical synthesis of stoichiometric $\mathrm{MgFe}_{2} \mathrm{O}_{4}$ spinel," Journal of Materials Science, vol. 20, no. 8, pp. 782-787, 2009.

[6] P. J. Van Der Zaag, J. J. M. Ruigrok, A. Noordermeer et al., "The initial permeability of polycrystalline MnZn ferrites: the influence of domain and microstructure," Journal of Applied Physics, vol. 74, no. 6, pp. 4085-4095, 1993.

[7] U. Erb, "Electrodeposited nanocrystals: synthesis, properties and industrial applications," Nanostructured Materials, vol. 6, no. 5-8, pp. 533-538, 1995.

[8] M. Pal and D. Chakravorthy, "Nanocrystalline magnetic alloys and ceramics," Sadhana, vol. 28, no. 1-2, pp. 283-297, 2003.

[9] C. J. O’Connor, E. Kolensnichenko, C. Carpenter et al., "Fabrication and properties of magnetic particles with nanometer dimensions," Synthetic Metals, vol. 122, no. 3, pp. 547-557, 2001.

[10] Y. Ichiyanagi, M. Kubota, S. Moritake, Y. Kanazawa, T. Yamada, and T. Uehashi, "Magnetic properties of Mg-ferrite nanoparticles," Journal of Magnetism and Magnetic Materials, vol. 310, no. 2, pp. 2378-2380, 2007.

[11] V. B. Kawade, G. K. Bichile, and K. M. Jadhav, "X-ray and infrared studies of chromium substituted magnesium ferrite," Materials Letters, vol. 42, no. 1, pp. 33-37, 2000.

[12] P. P. Hankare, U. B. Sankpal, R. P. Patil, P. D. Lokhande, and R. Sasikala, "Synthesis, characterization and catalytic activity of chromium substituted cobalt ferrospinels," Materials Science and Engineering B, vol. 176, no. 2, pp. 103-109, 2011.

[13] Y. Huang, Y. Tang, J. Wang, and Q. Chen, "Synthesis of $\mathrm{MgFe}_{2} \mathrm{O}_{4}$ nanocrystallites under mild conditions," Materials Chemistry and Physics, vol. 97, no. 2-3, pp. 394-397, 2006. 
[14] S. K. Pradhan, S. Bid, M. Gteshki, and V. Petkov, "Microstructure characterization and cation distribution of nanocrystalline magnesium ferrite prepared by ball milling," Materials Chemistry and Physics, vol. 93, no. 1, pp. 224-230, 2005.

[15] C. Cannas, A. Falqui, A. Musinu, D. Peddis, and G. Piccaluga, " $\mathrm{CoFe}_{2} \mathrm{O}_{4}$ nanocrystalline powders prepared by citrate-gel methods: synthesis, structure and magnetic properties," Journal of Nanoparticle Research, vol. 8, no. 2, pp. 255-267, 2006.

[16] S. Maensiri, M. Sangmanee, and A. Wiengmoon, "Magnesium ferrite $\left(\mathrm{MgFe}_{2} \mathrm{O}_{4}\right)$ nanostructures fabricated by electrospinning," Nanoscale Research Letters, vol. 4, no. 3, pp. 221-228, 2009.

[17] P. P. Hankare, V. T. Vader, N. M. Patil et al., "Synthesis, characterization and studies on magnetic and electrical properties of $\mathrm{Mg}$ ferrite with $\mathrm{Cr}$ substitution," Materials Chemistry and Physics, vol. 113, no. 1, pp. 233-238, 2009.

[18] C. Chen, Magnetism and Metallurgy of Soft Magnetic Materials, Dover, New York, NY, USA, 1986.

[19] M. Hisham, Alimuddin, M. Wasi Khan, S. Kumar, S. E. Shirsath, and R. Kumar, "Structural, dielectric and magnetic properties of nano-crystalline $\mathrm{Ni}-\mathrm{Mg}$ ferrites prepared by citrate-gel auto combustion method," Advanced Nanomaterials and Nanotechnology, vol. 143, pp. 215-224, 2013.

[20] M. Raghasudha, D. Ravinder, and P. Veerasomaiah, "Characterization of chromium substituted cobalt nano ferrites synthesized by citrate-gel auto combustion method," Advances in Materials Physics and Chemistry, vol. 3, no. 2, pp. 89-96, 2013.

[21] M. Raghasudha, D. Ravinder, and P. Veerasomaiah, "Characterization of nano-structured magnesium-chromium ferrites synthesized by citrate-gel auto combustion method," Advanced Material Letters, 2013.

[22] X. Qi, J. Zhou, Z. Yue, Z. Gui, and L. Li, "Effect of Mn substitution on the magnetic properties of MgCuZn ferrites," Journal of Magnetism and Magnetic Materials, vol. 251, no. 3, pp. 316-322, 2002.

[23] B. N. Figgis and R. S. Nyholm, "844. A convenient solid for calibration of the Gouy magnetic susceptibility apparatus," Journal of the Chemical Society, vol. 4, pp. 4190-4216, 1958.

[24] I. H. Gul and A. Maqsood, "Structural, magnetic and electrical properties of cobalt ferrites prepared by the sol-gel route," Journal of Alloys and Compounds, vol. 465, no. 1-2, pp. 227-231, 2008.

[25] Y. M. Yakovlev, E. V. Rubalikaya, and N. Lapovok, "Ferromagnetic resonance in lithium ferrite," Soviet Physics-Solid State, vol. 10, p. 2301, 1969.

[26] D. R. Mane, D. D. Birajdar, S. E. Shirsath, R. A. Telugu, and R. H. Kadam, "Structural and magnetic characterizations of Mn-NiZn ferrite nanoparticles," Physica Status Solidi (A) Applications and Materials Science, vol. 207, no. 10, pp. 2355-2363, 2010.

[27] S. Singhal and K. Chanda, "Cation distribution and magnetic properties in chromium-substituted nickel ferrites prepared using aerosol route," Journal of Solid State Chemistry, vol. 180, no. 1, pp. 296-300, 2007. 

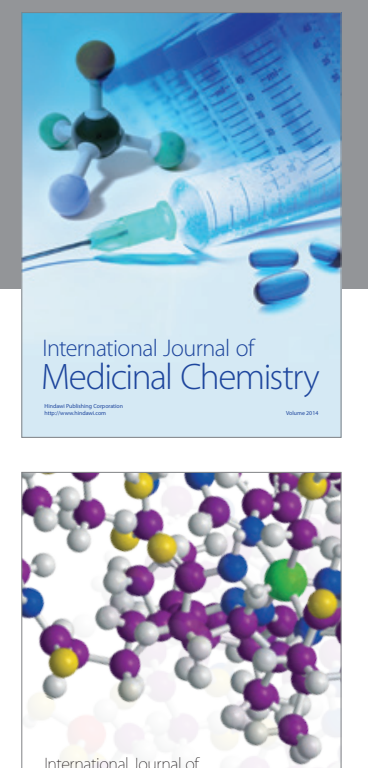

\section{Carbohydrate} Chemistry

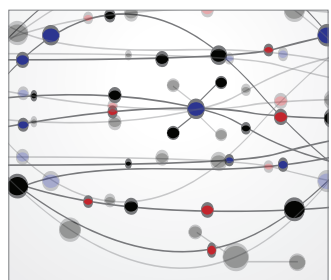

The Scientific World Journal
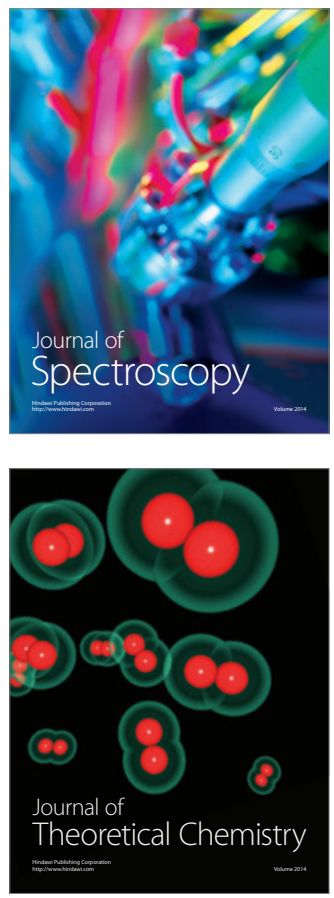
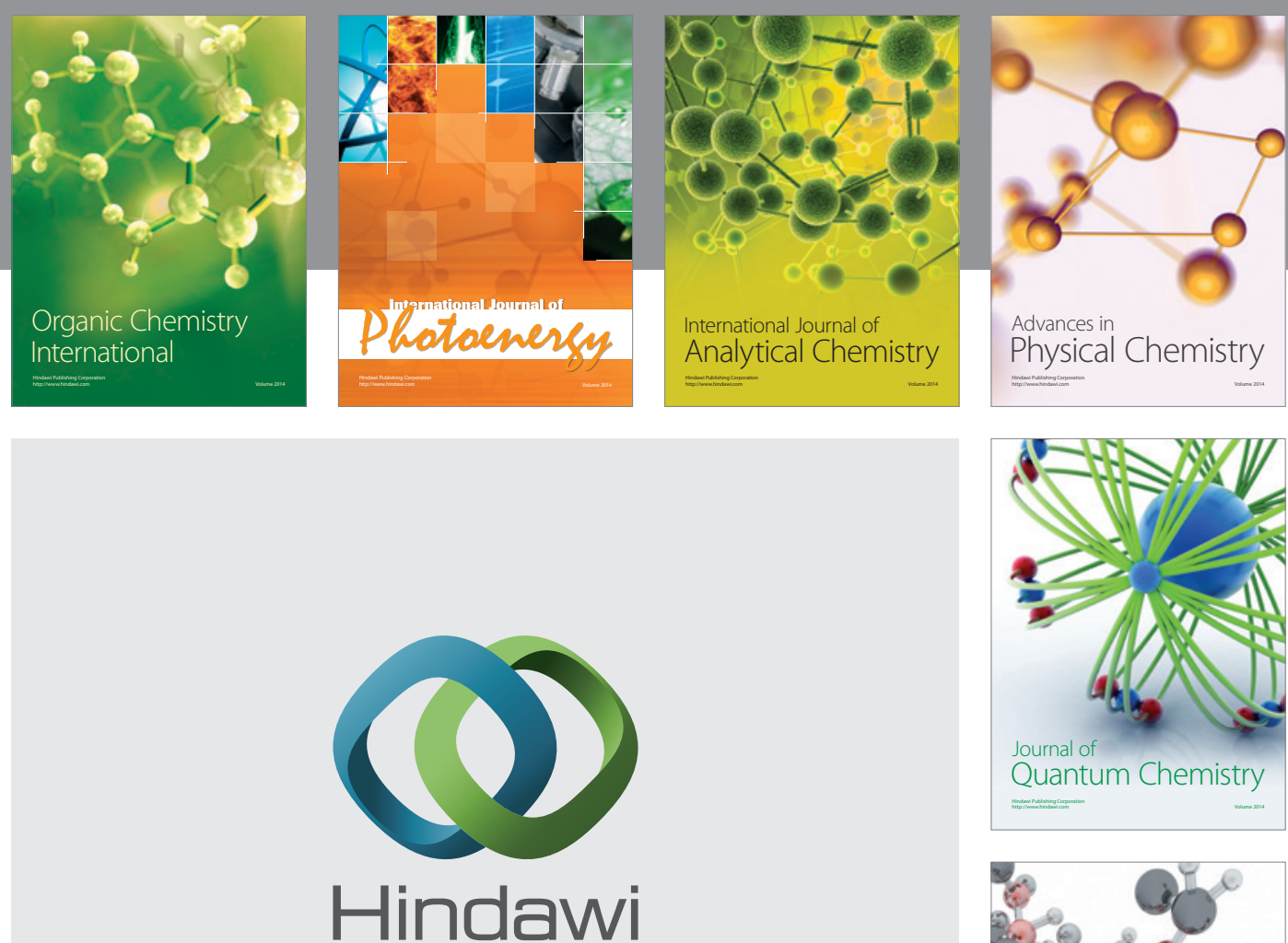

Submit your manuscripts at

http://www.hindawi.com

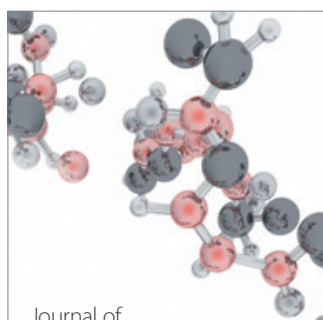

Analytical Methods

in Chemistry

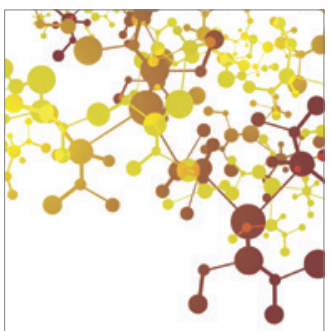

Journal of

Applied Chemistry

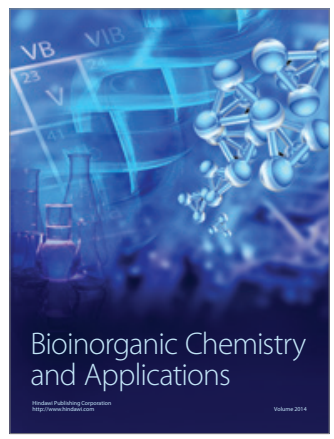

Inorganic Chemistry
